\title{
Article \\ Moisture Measurement in Paper and Cardboard Packaging Waste Bales for Recycling
}

\author{
Ana Silveira *D, João Cardoso, Maria José Correia and Graça Martinho \\ MARE-Marine and Environmental Sciences Centre, Department of Environmental Sciences and Engineering, \\ NOVA School of Science and Technology, Campus de Caparica, 2829-516 Caparica, Portugal; \\ vcardoso.j@gmail.com (J.C.); mjgc@fct.unl.pt (M.J.C.); mgm@fct.unl.pt (G.M.) \\ * Correspondence: ais@fct.unl.pt; Tel.: +351-212948397
}

Citation: Silveira, A.; Cardoso, J.; Correia, M.J.; Martinho, G. Moisture Measurement in Paper and Cardboard Packaging Waste Bales for Recycling. Appl. Sci. 2021, 11, 4586. https://doi.org/10.3390/app11104586

Academic Editor: Eric Guibal

Received: 5 April 2021

Accepted: 11 May 2021

Published: 18 May 2021

Publisher's Note: MDPI stays neutral with regard to jurisdictional claims in published maps and institutional affiliations.

Copyright: (c) 2021 by the authors. Licensee MDPI, Basel, Switzerland. This article is an open access article distributed under the terms and conditions of the Creative Commons Attribution (CC BY) license (https:// creativecommons.org/licenses/by/ $4.0 /)$.
Featured Application: Measuring moisture in bales of paper and cardboard packaging waste is of great importance in the transaction between the waste operators and the recycling industry. The traditional method (oven drying) to measure the moisture content of bales, in addition to requiring destruction of the bales, does not allow real-time measurement, which often generates distrust or conflicts between sellers and buyers at the time of negotiations. In this work, a new method was tested with a commercial device equipped with dielectric technology. The results are quite promising, providing a more time- and cost-effective, non-destructive and reliable method in the quality control of paper and cardboard packaging waste bales, which also contributes to greater trust between negotiators.

Abstract: Moisture content is a quality issue raised by recycling plants in the acceptance of paper and cardboard coming from waste streams. The current way to measure this parameter is by the oven drying method, which is a slow and invasive process, costing time and resources for the recyclers to do this type of quality control. An alternative to such a measurement technique is the use of plate-form devices which indirectly measure the moisture content using the dielectric properties of water and paper. This study has tested this method and developed a representative equation for the use of devices with these properties in the Portuguese market. For that, 48 wastepaper and cardboard bales were tested with both the traditional (oven drying) method and a commercial device equipped with dielectric technology. An equation that fits the studied reality $\left(R^{2}=0.76\right)$ was achieved, and possible problems regarding the use of this device were tested. The results showed that this type of device could be used as a time- and cost-saving, non-destructive and reliable method in the quality control of wastepaper and cardboard bales.

Keywords: waste packaging; moisture; oven drying; dielectric principle

\section{Introduction}

The knowledge of the moisture content in bales of paper and cardboard packaging waste for recycling is of great importance in the transaction between the waste operators and the recycling industry, specifically in the cost compensation values and in compliance with the technical specifications of recyclable material quality currently in force, namely where moisture content values higher than $25 \%$ cause bales to be rejected [1].

Presently, the applied method in Portugal's packaging recovery organization Sociedade Ponto Verde (SPV) [1] is the gravimetric method, where three samples of $50 \mathrm{~g}$ of paper and cardboard are dried in an oven at $105^{\circ} \mathrm{C}$ until a constant weight is achieved [2]. However, this method is time-consuming and destructive because the paper and cardboard bales are destroyed during sample collection.

There are technologies that try to simplify the procedure of measuring the moisture in bales of paper and cardboard packaging waste to make the procedure more expeditious 
and agile, including noninvasive techniques such as measuring the electrical resistance of the materials by a dielectric constant, microwaves and time domain reflectometry (TDR).

These different techniques have been used in a diversity of sectors for the measurement of moisture content. Gawande et al. [3] used the electrical resistance technique to measure the moisture in urban solid waste samples. Lawrence et al. [4] determined the moisture of bales of hay for use in the construction industry using metallic rods, where the electrical resistance was used for the indirect determination of the water content. Ek et al. [5] used the dielectric method to study the moisture, among other parameters, in cellulose and printing paper. Trabelsi et al. [6] measured the moisture content and density of peanut shell pellets using the nondestructive microwave technique. The TDR technique was used by Noborio [7] to measure the moisture content in soil.

Among the nondestructive techniques available, the present work was developed using equipment in which the operating mode was similar to that described by Ek et al. [5] and Fuchs et al. [8]; both used capacitive sensing methods, integrating the material permittivity of water $\left(\varepsilon_{\mathrm{r}}\right.$, water of 80$)$ and other materials. The variation of the material permittivity, and hence the variation of the moisture content, could be measured as a change in capacitance when the test material was located between two electrodes. Ek et al. determined the dielectric factor of cellulose to be 4.35 , which can be a reference for the cardboard and paper bales studied on the current work. Some devices have an output voltage which is linearly related with the change in the capacitance, as shown in Chetpattananondh et al. [9].

Additionally, Mireei et al. [10] explored the dielectric properties of materials to determine the moisture content in dates by using parallel plates, having reached promising results by correlating the voltage measurements and moisture contents of the fruits sampled.

According to Nelson's definition [11], the dielectric constant of a material is associated with its capacity to store energy in its electric field, and the loss factor is associated with the ability of that material to absorb or dissipate energy, which has been converted from electrical to thermal energy. According to the same author, the electric capacitance of two conducting parallel plates separated by an empty space will be multiplied by the dielectric constant value of a material occupying that same space [11]. Therefore, the greater the dielectric constant of the material between the two parallel plates, the greater the final measured voltage.

In the present work, the material in which the moisture content was measured was paper and cardboard packaging waste. It was used a commercially available equipment that combined the measurement of an electric voltage and the measured reaction to an electric field of water, of which the dielectric constant was approximately 82 [12], and other materials, including cardboard, paper and air, with dielectric constants ranging between 1.0 to 4.0 .

The equipment used included a $60 \times 10 \mathrm{~cm}$ flat plate that was inserted into each bale and through which an electric field was passed to measure the water present in the middle of the bale. This is a noninvasive method, in that the bales do not have to be undone to perform the measurements.

This technology, coupled with portable equipment that is easy to use and handle, enables fast moisture measurement in paper and cardboard packaging waste bales. This can be a piece of technology that helps with the day-to-day separation and treatment of these materials, since it will save time in the acquisition of quality data on the bales produced, having a primary focus on their moisture content. In this way, cooperation between the stakeholders of the transaction chain of these recyclables is increased. This is possible if the bales are usable, allowing the introduction of material tracking methods along the entire value chain.

This type of technology may have disadvantages of the effective depth of measurement, the occurrence of interference due to the presence of contaminants such as metals, fats or surface water as well as the inevitable contamination from the transport and handling of bales. 
In order to test and validate the reliability of the method inherent to the equipment, it is important to perform a calibration for the type of materials in a given market where the equipment is used so that the obtained moisture results are reliable and generate agreement among the stakeholders.

According to Cerny [13], the most reliable way to calibrate a device for measuring moisture in this type of operation (i.e., one having constant material type and arrangement conditions) is the empirical calibration of the permittivity of the materials regarding a reference method, as is the case with the gravimetric method. The authors considered this to be the most reliable method, though it is one that consumes more time.

Regarding the dearth of papers dedicated to the nondestructive moisture content measurement of paper and cardboard, the present study aims to produce some data to correlate the voltage measurements and the moisture content of the wastepaper and cardboard bales. The four main goals this paper seeks to address are (1) testing the measuring method to see if it is an accurate and efficient yet rapid method for meeting operators' moisture control requirements for recycled paper and cardboard; (2) developing a calibration curve, in the form of an equation, based on the voltage measurements for bales of paper and cardboard packaging waste present in the Portuguese market so that this type of technology can be introduced in this market and moisture measurements can be easier to obtain compared with the current method [1]; (3) understanding the variables that most influence voltage measurements, such as the moisture content, weight, specific gravity and bale compression density; and (4) suggesting a measurement procedure appropriate to the type of equipment tested.

\section{Materials and Methods}

\subsection{Equipment Applied}

The equipment tested for this study was an $\mathrm{EMCO}^{\circledR}$ model AP 500-M3 moisture meter, shown in Figure 1. This system operates on the basis of the dielectric measurement principle and under the conditions recommended by the manufacturer (Table 1).

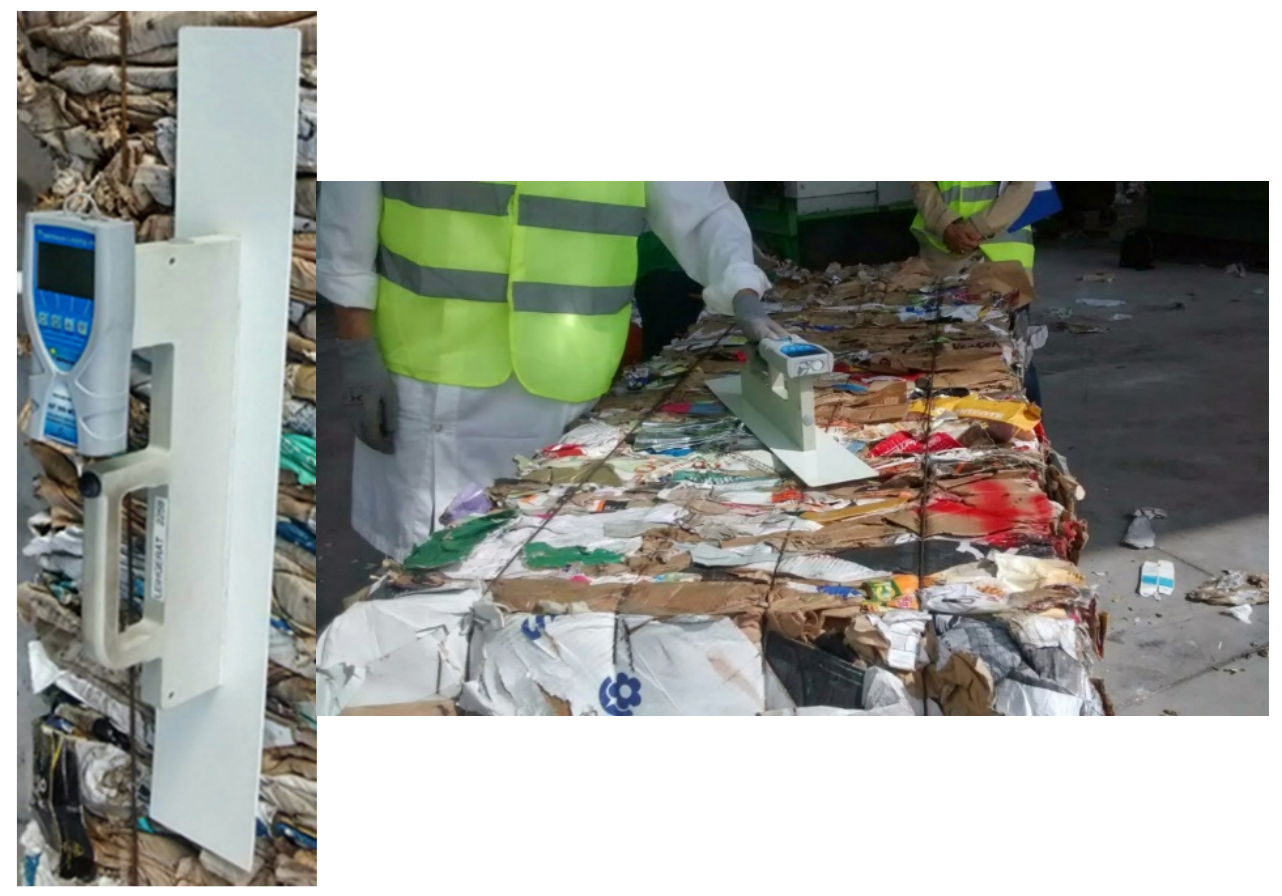

Figure 1. Equipment used in the project: $\mathrm{EMCO}^{\circledR}$ model AP 500-M3. 
Table 1. $\mathrm{EMCO}^{\circledR}$ model AP 500-M3 operational characteristics, according to the manufacturer.

\begin{tabular}{cc}
\hline Equipment Characteristics & \\
\hline Resolution & $0.5 \%$ \\
Operative temperature & $0-40{ }^{\circ} \mathrm{C}$ \\
Relative humidity of the ambient air & $30-70 \%$ \\
Effective measurement depth & $30 \mathrm{~cm}$ \\
Maximum measurement depth & $50 \mathrm{~cm}$ \\
Detection limit (ww) & $1-50 \%$ \\
\hline
\end{tabular}

The equipment was $60 \mathrm{~cm}$ in height and $10 \mathrm{~cm}$ in width and provided instantaneous moisture measurements. The equipment must be properly seated in the material to be measured so that there is no excess air between the measuring plate and the bale surface.

\subsection{Bale Analysis Methodology}

The methodology presented below was replicated 23 times in a total of 11 waste treatment facilities. In seven of the facilities, wastepaper and cardboard came from selection bins, and they were sorted and baled. In the other four facilities operated by recycling companies, bales were produced from materials that had undergone more refined sorting.

Forty-eight bales were analyzed in total. In each analysis, bales of recently produced paper and cardboard waste were selected, taking into consideration the condition of the bales' surficial characteristics. For example, the surfaces selected were as flat as possible, with a minimum number of empty spaces and not presenting evidence of significant contamination by fats or metals.

The bales were weighed using a scale, and their dimensions were measured for weight and volume determination. The parameters of the medium (in this case, the bales of paper and cardboard packaging waste), such as the density and the content of cardboard packaging, needed be evaluated in order to study any interference with the moisture measurements with the tested equipment. The compression density, a parameter that is advanced by the manufacturer and calculated according to Equation (1), must also be evaluated for the same purpose:

$$
\text { Compression density }\left[\frac{\mathrm{kg}}{\mathrm{m}^{3}}\right]=\frac{\text { Specific Weight }\left[\frac{\mathrm{kg}}{\mathrm{m}^{3}}\right]}{1+\frac{\text { Moisture content }[\%]}{100 \%}}
$$

After determining the bale dimensions, the "front" and "back" surfaces were defined as shown in Figure 2, and measurements were made with the equipment in volts (V). The number of measurements per face was variable, being at least five per face up to the maximum possible number of measurements according to the bale size. Then, the arithmetic average of these measurements was calculated, thus representing the moisture content of the measured bale.

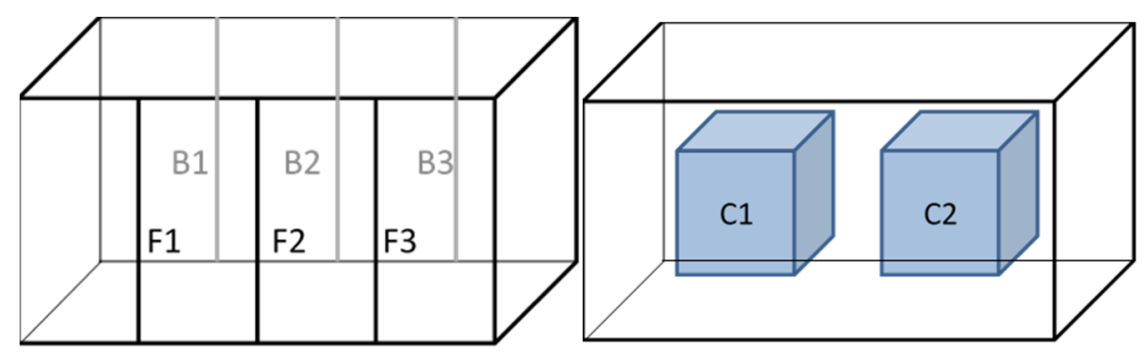

Figure 2. Sampling collection location, front (F) and back (B) of the bales divided into the three sampling sections, plus the two samples collected in each center of a half-bale (C). 
Once measurements were performed, samples of paper and cardboard waste were collected, and the moisture content was determined using the conventional oven drying method, carried out according to the standard ISO 287 method [2]. For this purpose, eight samples were taken from each bale. Six of them came from the first $30 \mathrm{~cm}$ layer of each the front face (F1, F2 and F3) and from the back face (B1, B2 and B3) (Figure 2). The bottom and the top faces were discarded because they were not used for the measuring equipment due to contamination and the presence of metal straps. The other two samples were collected from the center of each half-bale ( $\mathrm{C} 1$ and $\mathrm{C} 2$ ). This method allowed the sampling of a fair representation of the bale materials and moisture distribution and allowed determination of the moisture content from the oven drying method at the same location as the equipment measurements. Moisture content, on a wet basis, was determined by dividing the oven dry mass by the initial (wet) mass according to Equation (2):

$$
\text { Moisture content }(\mathrm{MC}), \%=\frac{\text { Initial mass }- \text { Oven dry mass }}{\text { Initial mass }} \times 100 \%
$$

\subsection{Data Analysis}

Data analysis was carried out initially to understand the influence of the oven moisture content, weight, density, compression density and material type on the measurements of the equipment. The coefficient of determination $\left(R^{2}\right)$ was calculated with those parameters and the measured voltages in each bale. This test had the merit of understanding the equipment limitations and helped to set the measurement recommendations.

Afterward, a linear regression model was applied to the equipment measurements, and the moisture determined by the oven drying method, resulting in an equation tuned to the studied samples.

\section{Results and Discussion}

The bale characteristics along with the values of the laboratory moisture determination are displayed in Table 2. Each bale is associated with its cardboard packaging content, moisture content by the oven drying method, voltage measurements, weight, density and compression density, calculated according to Equation (1). Bales were named with a letter designating their batch and recycling plant.

The analyzed bales covered a great variability in characteristics, since their weights varied from $240 \mathrm{~kg}$ to $1320 \mathrm{~kg}$. Thus, the range of weight classes of bales existing in the market, including small sizes (200-400 kg), medium sizes (401-600 kg) and large sizes (601-1200 kg), were covered. This range of weights is described by the SPV [1]. The density varied from $335 \mathrm{~kg} / \mathrm{m}^{3}$ to $605 \mathrm{~kg} / \mathrm{m}^{3}$. The compression density varied between $308 \mathrm{~kg} / \mathrm{m}^{3}$ and $526 \mathrm{~kg} / \mathrm{m}^{3}$.

\subsection{Moisture Content Determined by the Oven Drying Method}

A relevant output of this work is the oven moisture content determination of the paper and cardboard packaging waste bales produced in geographically different places with different compositions of cardboard content all during the winter season. Therefore, it is possible to get an idea of the expected moisture for these kinds of bales at this time of year.

The most representative moisture class of the analyzed bales was that of 10-13\% moisture, representing a $43.8 \%$ frequency. Bales with moisture contents between $7 \%$ and $10 \%$ represented $20.8 \%$ of the total bales sampled, and bales with moisture contents between $13 \%$ and $16 \%$ represented a $25.0 \%$ frequency. Only four bales (frequency of $8.3 \%$ ) showed moisture contents ranging from $16 \%$ to $19 \%$. Therefore, $64.6 \%$ of the analyzed bales had moisture contents between $7 \%$ and $13 \%$. Bales with moisture contents above $16 \%$ were rare, representing only $10.4 \%$ of the sample. 
Table 2. Characteristics of the 48 analyzed bales.

\begin{tabular}{|c|c|c|c|c|c|c|}
\hline Bale & $\begin{array}{l}\text { Cardboard } \\
\text { Content }(\%)\end{array}$ & $\begin{array}{l}\text { Moisture Content } \\
\text { in Oven (\%) }\end{array}$ & Voltage (V) & Weight (kg) & Density (kg/m³) & $\begin{array}{c}\text { Compression } \\
\text { Density }\left(\mathrm{kg} / \mathrm{m}^{3}\right)\end{array}$ \\
\hline A1 & 100 & 15.1 & 0.685 & 1199 & 508 & 441 \\
\hline $\mathrm{A} 2$ & 100 & 8.3 & 0.489 & 1034 & 506 & 467 \\
\hline B1 & 85 & 16.3 & 0.807 & 1289 & 530 & 455 \\
\hline $\mathrm{B} 2$ & 85 & 15.4 & 0.876 & 1314 & 605 & 524 \\
\hline $\mathrm{C} 1$ & 90 & 9.1 & 0.486 & 694 & 403 & 370 \\
\hline $\mathrm{C} 2$ & 90 & 10.0 & 0.508 & 782 & 380 & 346 \\
\hline D1 & 52 & 9.1 & 0.490 & 240 & 335 & 308 \\
\hline D2 & 52 & 13.3 & 0.680 & 339 & 416 & 368 \\
\hline E1 & 60 & 10.6 & 0.532 & 795 & 443 & 401 \\
\hline E2 & 60 & 11.5 & 0.528 & 783 & 454 & 407 \\
\hline $\mathrm{F} 1$ & 44 & 11.3 & 0.543 & 684 & 507 & 455 \\
\hline $\mathrm{F} 2$ & 44 & 19.4 & 0.670 & 656 & 512 & 429 \\
\hline G1 & 60 & 10.9 & 0.455 & 772 & 469 & 423 \\
\hline G2 & 60 & 13.4 & 0.511 & 853 & 525 & 463 \\
\hline $\mathrm{H} 1$ & 60 & 9.9 & 0.453 & 798 & 550 & 500 \\
\hline $\mathrm{H} 2$ & 60 & 12.3 & 0.531 & 845 & 591 & 526 \\
\hline I1 & 60 & 10.3 & 0.520 & 940 & 579 & 525 \\
\hline I2 & 60 & 9.8 & 0.491 & 815 & 502 & 457 \\
\hline $\mathrm{J} 1$ & 55 & 8.1 & 0.468 & 809 & 511 & 473 \\
\hline $\mathrm{J} 2$ & 55 & 8.1 & 0.467 & 812 & 500 & 462 \\
\hline K1 & 52 & 8.3 & 0.499 & 419 & 483 & 446 \\
\hline K2 & 52 & 14.1 & 0.720 & 538 & 552 & 483 \\
\hline L1 & 94 & 8.7 & 0.451 & 358 & 455 & 418 \\
\hline L2 & 94 & 8.7 & 0.452 & 379 & 378 & 348 \\
\hline M1 & 52 & 12.9 & 0.731 & 585 & 571 & 506 \\
\hline M2 & 52 & 14.3 & 0.761 & 540 & 571 & 500 \\
\hline M1 & 94 & 11.5 & 0.562 & 435 & 440 & 395 \\
\hline M2 & 94 & 10.3 & 0.569 & 426 & 433 & 392 \\
\hline N1 & 40 & 11.2 & 0.668 & 336 & 473 & 425 \\
\hline N2 & 40 & 12.2 & 0.609 & 290 & 395 & 352 \\
\hline O1 & 62 & 13.1 & 0.714 & 831 & 520 & 460 \\
\hline $\mathrm{O} 2$ & 62 & 12.2 & 0.591 & 825 & 524 & 468 \\
\hline $\mathrm{P} 1$ & 60 & 16.7 & 0.673 & 819 & 490 & 420 \\
\hline P2 & 60 & 12.7 & 0.585 & 743 & 489 & 433 \\
\hline Q1 & 60 & 15.4 & 0.771 & 996 & 582 & 504 \\
\hline Q2 & 60 & 17.3 & 0.991 & 982 & 556 & 474 \\
\hline$\widehat{\mathrm{Q} 3}$ & 60 & 15.8 & 0.779 & 879 & 519 & 448 \\
\hline Q4 & 60 & 18.8 & 0.776 & 743 & 489 & 411 \\
\hline R1 & 94 & 13.2 & 0.532 & 752 & 491 & 434 \\
\hline $\mathrm{R} 2$ & 94 & 13.1 & 0.575 & 779 & 501 & 443 \\
\hline R3 & 94 & 13.1 & 0.643 & 776 & 506 & 447 \\
\hline $\mathrm{R} 4$ & 94 & 11.9 & 0.524 & 729 & 467 & 418 \\
\hline S1 & 94 & 10.5 & 0.617 & 1172 & 547 & 495 \\
\hline $\mathrm{S} 2$ & 94 & 10.4 & 0.645 & 1125 & 580 & 525 \\
\hline S3 & 94 & 11.2 & 0.604 & 956 & 500 & 450 \\
\hline S4 & 94 & 10.5 & 0.640 & 1320 & 550 & 498 \\
\hline $\mathrm{T} 1$ & 94 & 11.5 & 0.545 & 712 & 457 & 410 \\
\hline $\mathrm{T} 2$ & 94 & 11.2 & 0.516 & 709 & 462 & 416 \\
\hline
\end{tabular}

\subsection{Voltage Measurement Variability Regarding Bale Characteristics}

Volts $(V)$ were the measurement unit of the equipment in operation in this study. Defining which parameters can interfere with the voltages becomes important for performing the correct operation of this type of equipment.

Taking the voltage data as the basis of the equipment operation, the study of the $R^{2}$ between equipment operation and the measured parameters of each bale is presented 
in Table 3. Thus, this is intended to verify the parameter's influence on the equipment in operation.

Table 3. Coefficient of determination $\left(R^{2}\right)$ relating different variables and voltage measurements.

\begin{tabular}{cc}
\hline Parameter & $\mathbf{R}^{\mathbf{2}}$ \\
\hline Moisture & 0.63 \\
Density & 0.23 \\
Weight & 0.11 \\
Compression density & 0.11 \\
Type of material & 0.01 \\
\hline
\end{tabular}

It should be noted that the moisture content of the bales was shown to be the variable that most influenced the voltage measurements' behavior, as expected, since the operation of the equipment was based on the difference in the dielectric constants of water and paper and cardboard, as previously explained. No significant correlation was found between those parameters and the measured voltage; thus, the moisture content was effectively the parameter that made the voltage vary. Mireei et al. [10] reached similar results.

The variable compression density, shown in Equation (1), presented a poor correlation with the measurements in volts. The analyzed bales had similar compression ranges, since they were subjected to similar pressures used in the presses by the waste operators. It would be expected that this parameter would be less significant to the present analysis, and that the same would be true for the density.

Overall, it was not expected that the physical characteristics of the bales would interfere in the dielectric principle regarding the indirect moisture measurements.

\subsection{Calibration Equation}

As previously mentioned, a calibration equation was developed so that the equipment could be used with more accuracy as close as possible to the bales to be analyzed in the daily use of the equipment.

A linear regression model was applied using voltage and oven moisture to develop the equation. However, a previous residuals study using the Cooks distance method was conducted to identify possible outliers, as displayed in Figure 3.
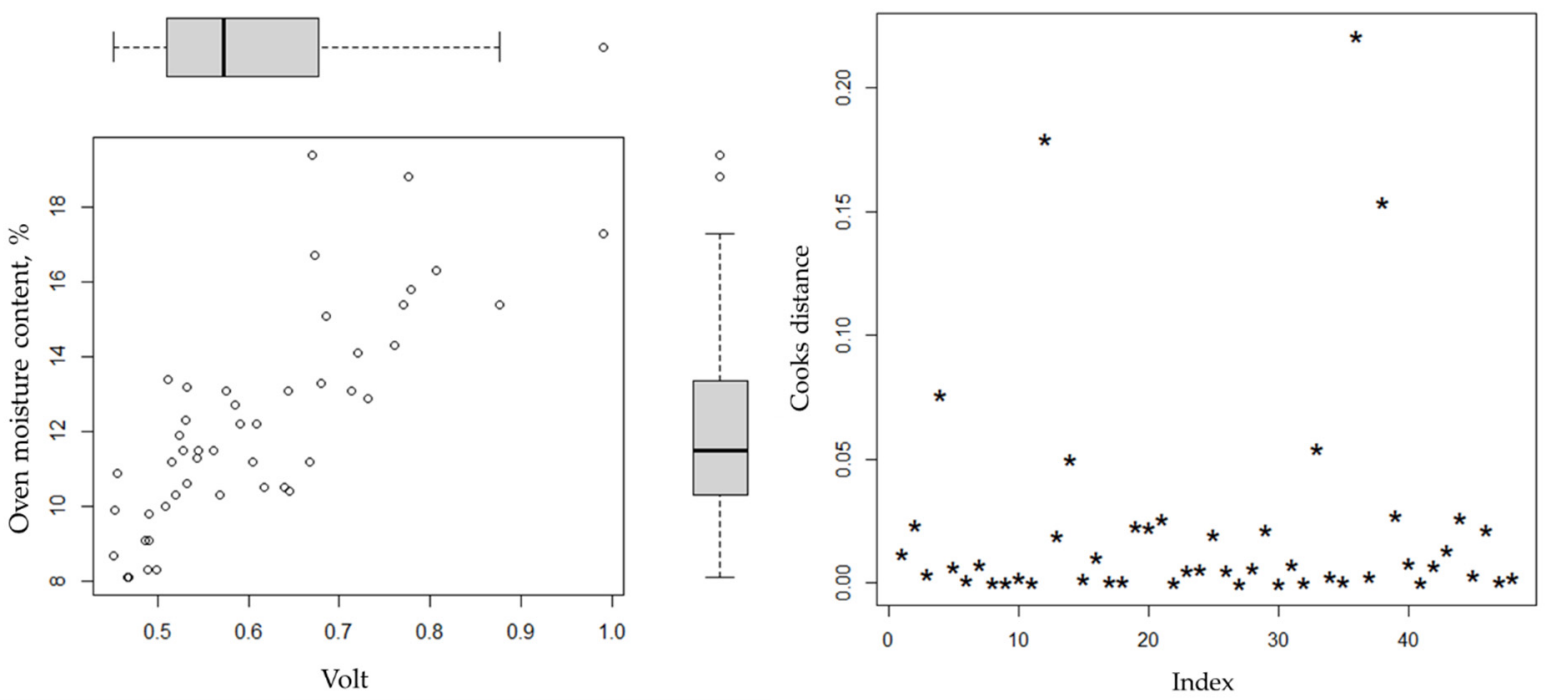

Figure 3. Outliers' identification with the R software boxplot and Cooks distance method. The outliers were the F2, Q2 and Q4 bales. 
Three outliers were identified in Figure 3. In particular, bales F2 and Q4 presented a lower voltage measurement with the high moisture content, and the opposite was true for bale Q2. Therefore, they were excluded so as not to interfere with the model. The calibration equation was calculated with a linear regression model as presented in Figure 4.

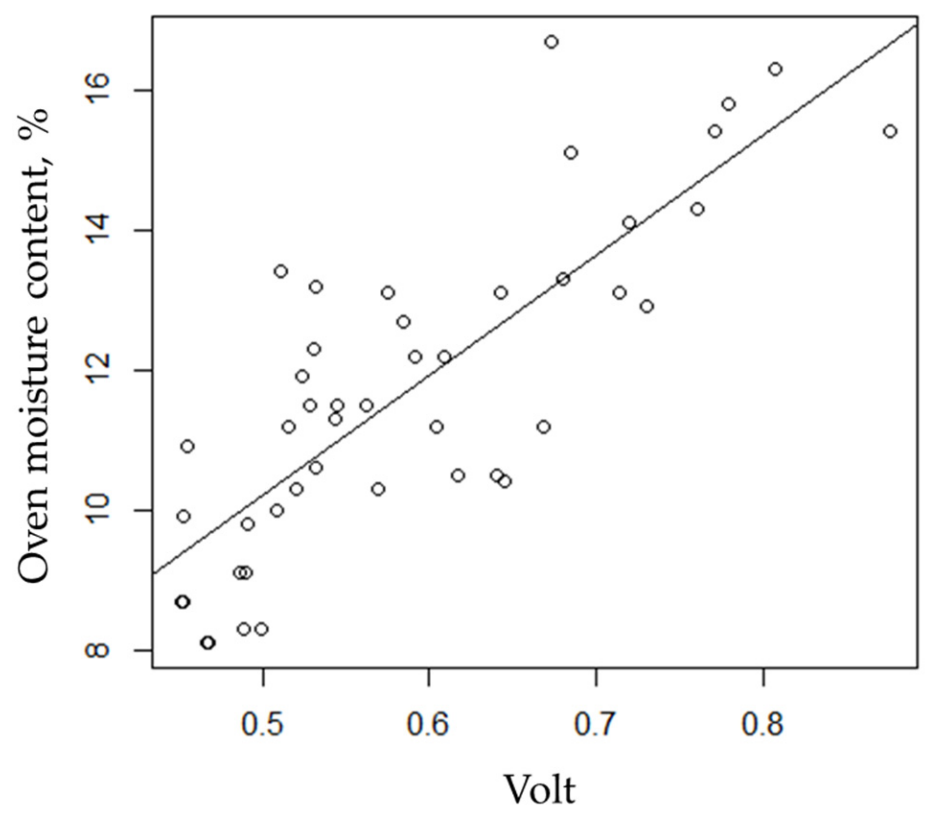

Figure 4. Linear regression of $\mathrm{V}$ and oven moisture (\%). $\mathrm{MC}=17.131 \mathrm{~V}+1.635$, residual standard error: 1.366 at 43 degrees of freedom, multiple $R^{2}$ of 0.655 , adjusted $R^{2}$ of 0.647 , F-statistic of 81.79 on 1 and 43 DF; $p$-value of $1.663 \times 10^{-11}$.

A linear regression of the voltage and oven moisture values without outliers determined the calibration equation to be MC $\%=17.131 \mathrm{~V}+1.635$, with an $\mathrm{R}^{2}$ of 0.655 . This is a low correlation. However, cardboard is a rough material, and the standard deviation for the moisture content, measured by the oven drying method, was $1.349 \%$. The comparison for the preinsert programs in the equipment (S4, S5 and S6) had shown lower coefficients of determination and higher standard deviations (Figure 5), thus demonstrating the calibration equation generating more accurate results for the purpose of measuring moisture in cardboard bales.

Due to the lack of opportunity to test the calibration equation on bales after the conclusion of the project, to test the model, a K-fold cross validation with $\mathrm{K}=10$ was performed with $R$ software. The obtained resampling results were $R M S E=1.333, R^{2}=0.764$ and $\mathrm{MAE}=1.112$, with a mean squared error of 1.333 , which is acceptable regarding the usage of the equipment in the real operational environment, and a higher $R^{2}$ of 0.764 . Despite there not being a strong $R^{2}$, the results were better than the linear regression $\left(R^{2}\right.$ of 0.655), suggesting that with further sampling, the model can be improved. The results are consistent with previous work using similar technology, despite differences in the studied materials. Kokua et al. [14] reported a maximum mean error of $2.16 \%$ when using a coplanar dielectric device to measure palmwood moisture content, and Chetpattananondh et al. [9] reported an RSME equal to $2.1 \%$ for a similar device. 

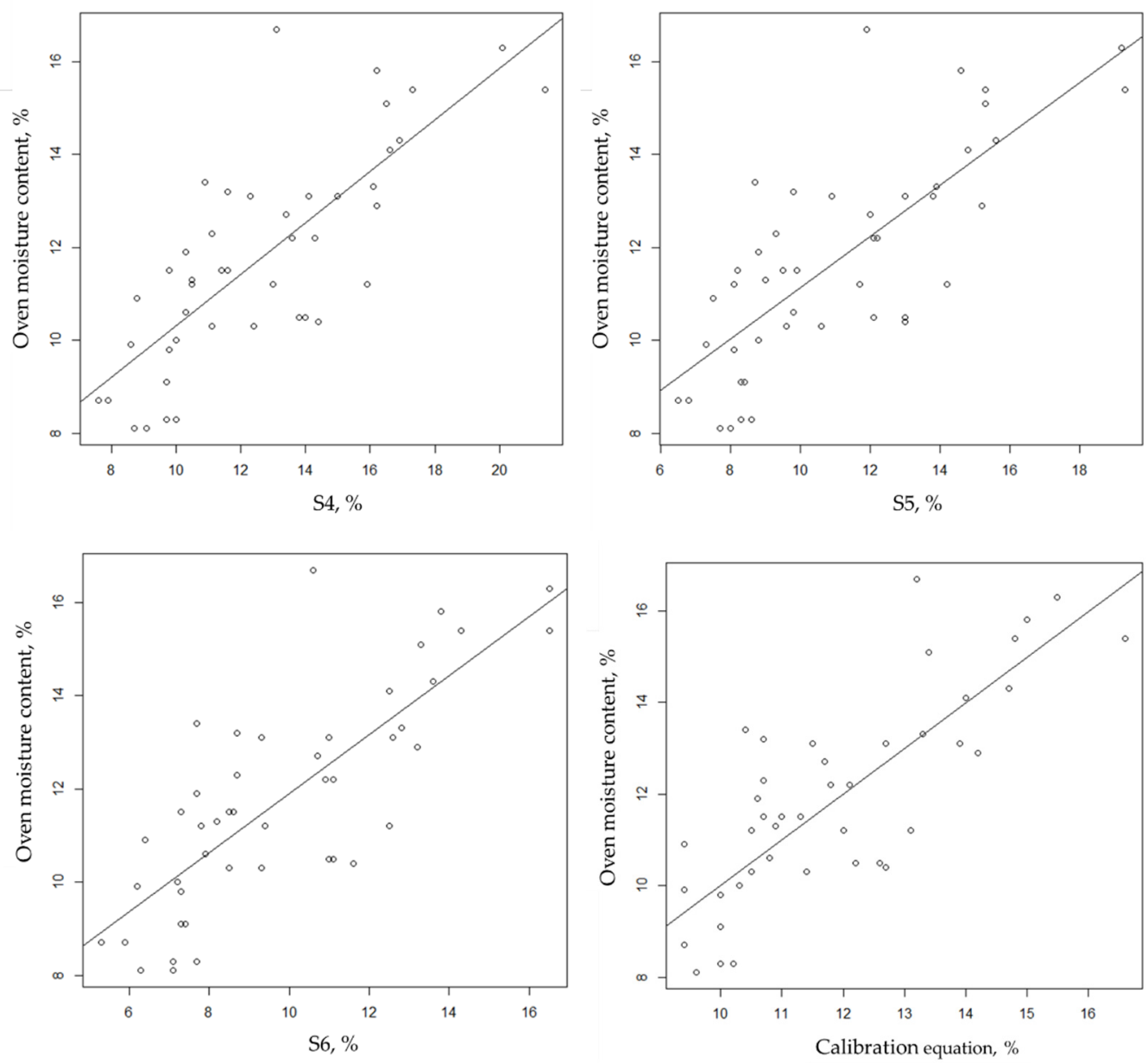

Figure 5. Linear regression of the preinstalled programs of the equipment (S4, S5 and S6) versus the oven moisture (OM $(\%))$. The standard deviations of $\mathrm{d}=\mathrm{si}-\mathrm{OM}$ were $\mathrm{S} 4=2.037$ and $\mathrm{R}^{2}=0.612, \mathrm{~S} 5=2.059$ and $\mathrm{R}^{2}=0.587$ and $\mathrm{S} 6=1.768$ and $R^{2}=0.615$. Calibration equation $=1.349$ and $R^{2}=0.656$.

Such error is explained by the amplitude of the results and the dispersion of the correlation between the oven moisture content and the voltage, especially in bales with higher moisture contents. This is consistent with the findings of Korkua, et al. [14]. Therefore, it is necessary to collect further data to make the equation more robust. Nevertheless, it is useful to recommend the use of such equipment in bales that have faces with the fewest empty spaces possible and no contaminants, such as excess superficial moisture, metals or fats. Those limiting factors were identified in the file measurements and help to explain the variability of the measurements.

\section{Conclusions}

The conclusions of this project indicate that the measurement method based on the dielectric constants of the materials is appropriate for use in equipment with a similar structure to that used in this study for the standard and quick determination of moisture in bales of paper and cardboard packaging waste.

From this study, it is necessary to highlight the produced equation that relates the voltage and the corresponding moisture. This relationship is intrinsically associated with the type of material (waste of paper and cardboard packaging) and considers the density inherent in the bales produced by the presses currently in operation. Therefore, this equation remains valid until some of these parameters change significantly.

The advantages of this equipment are the representativeness of the measurements in terms of the volume that can be analyzed, compared to the current procedure of moisture 
determination by the oven drying method $(3 \times 50 \mathrm{~g})$ [1,2], and the ease of use, allowing the taking of many measurements in a short time with an acceptable and known associated error.

To provide the most reliable results for Portuguese recyclers, it is recommended that the custom calibration equation for this equipment and the given test conditions be applied, accounting for an error of \pm 1.4 p.p. in the final mean of the measurements.

Measurement of the moisture content in bales of paper and cardboard packaging waste using this indirect and noninvasive measurement principle requires several assumptions for its use. The measured faces cannot be overly wet, as this may result in a wrong measurement due to the excessive interaction between the water and the applied electrical voltage. This happens in bales in which the first 10-15 cm of depth are wet and the inside material remains dry. It is therefore recommended that measurements using this equipment be performed on vertical faces without containment wires and which have not been exposed to rain or other natural precipitation. The bottom of the bale, which rests on the floor, should also be avoided because it is usually dirty due to contact with the ground when it is produced. This dirt would also interfere with the correct measurement.

To date, no similar work has been reported on a similar scale, so results that include the adopted methodology and the produced calibration equation are a basis for the future development of similar technology and equipment. It is also suggested that the equipment be used either by recyclers in charge of take back or by producers at the entrance and exit of their installations. In the place of production of the bales, it is necessary to analyze the moisture of some units of each lot and to mark them with this information by means of a bar code or another method when the load is received by either the recycler in charge of take back or the final recycler. The moisture measurements carried out can be confirmed by a new measurement of the bales previously marked by the preparer of that lot of paper and cardboard bales.

Further work must be promoted to improve and prove to what depth this measurement principle can reach into paper and cardboard bales in order to increase the reliability of the data obtained through this measurement method.

Author Contributions: Conceptualization, A.S.; methodology, A.S. and J.C.; software, J.C.; validation, J.C.; formal analysis, A.S.; investigation, J.C. and M.J.C.; data curation, J.C. and M.J.C.; writingoriginal draft preparation, J.C.; writing-review and editing, A.S., J.C. and G.M.; supervision, G.M.; project administration, A.S.; funding acquisition, A.S. All authors have read and agreed to the published version of the manuscript.

Funding: This research was funded by Sociedade Ponto Verde (SPV) and was supported by the Marine and Environmental Sciences Centre (MARE), which is financed by national funds from FCT /MCTES (UIDB/04292/2020).

Acknowledgments: This study was developed in partnership with Sociedade Ponto Verde (SPV).

Conflicts of Interest: The authors declare no conflict of interest. The funders had no role in the design of the study; in the collection, analyses, or interpretation of data; in the writing of the manuscript, or in the decision to publish the results.

\section{References}

1. SPV. Especificações Técnicas Para a Retoma de Resíduos de Embalagens de Papel/Cartão (Technical Specifications for Recovery of Paper/Cardboard Packaging Waste); Sociedade Ponto Verde: Algés, Portugal, 2007; pp. 4-10.

2. ISO. Paper and Board-Determinations of Moisture Content of a Lot-Oven-Drying Method; ISO 287; International Organization for Standardization: Geneva, Switzerland, 2009.

3. Gawande, N.A.; Reinhart, D.R.; Thomas, P.A.; McCreanor, P.T.; Townsend, T.G. Municipal solid waste in situ moisture content measurement using an electrical resistance sensor. Waste Manag. 2003, 23, 667-674. [CrossRef]

4. Lawrence, M.; Heath, A.; Walker, P. Determining moisture levels in straw bale construction. Constr. Build. Mater. 2009, 23, 2763-2768. [CrossRef]

5. Ek, R.; Hill, R.M.; Newton, J.M. Low frequency dielectric spectroscopy characterization of microcrystalline cellulose, tablets and paper. J. Mater. Sci. 1997, 32, 4807-4814. [CrossRef] 
6. Trabelsi, S.; Paz, A.M.; Nelson, S.O. Microwave dielectric method for the rapid, non-destructive determination of bulk density and moisture content of peanut hull pellets. Biosyst. Eng. 2013, 115, 332-338. [CrossRef]

7. Noborio, K. Measurement of soil water content and electrical conductivity by time domain reflectometry: A review. Comput. Electron. Agric. 2001, 31, 213-237. [CrossRef]

8. Fuchs, A.; Moser, M.J.; Zang, H.; Bretterklieber, T. Using capacitive sensing to determine the moisture content of wood pelletsInvestigations and application. Int. J. Smart Sens. Intell. Syst. 2009, 2, 293-308. [CrossRef]

9. Chetpattananondh, P.; Thongpull, K.; Chetpattananondh, K. Interdigital capacitance sensing of moisture content in rubber wood. Comput. Electron. Agric. 2017, 142, 545-551. [CrossRef]

10. Mereei, S.A.; Bagheri, R.; Sadegui, M.; Shahraki, A. Developing an electronic portable device based on dielectric powerspectroscopy for non-destructive prediction of date moisture content. Sens. Actuators A Phys. 2016, 247, 289-297. [CrossRef]

11. Nelson, S.O. Fundamentals of dielectric properties measurements and agricultural applications. J. Microw. Power Electromagn. Energy 2010, 44, 98-113. [CrossRef]

12. Simonson, T. Accurate calculation of the dielectric constant of water from simulations of a microscopic droplet in vacuum. Chem. Phys. Lett. 1996, 250, 450-454. [CrossRef]

13. Cerny, R. Time-domain reflectometry method and its application for measuring moisture content in porous materials: A review. Measurement 2009, 42, 329-336. [CrossRef]

14. Korkua, S.K.; Sakphrom, S. Low-cost capacitive sensor for detecting palm-wood moisture content in real-time. Heliyon 2020, 6 , e04555. [CrossRef] [PubMed] 